Palestinian Ministry of Health (MoH) referrals
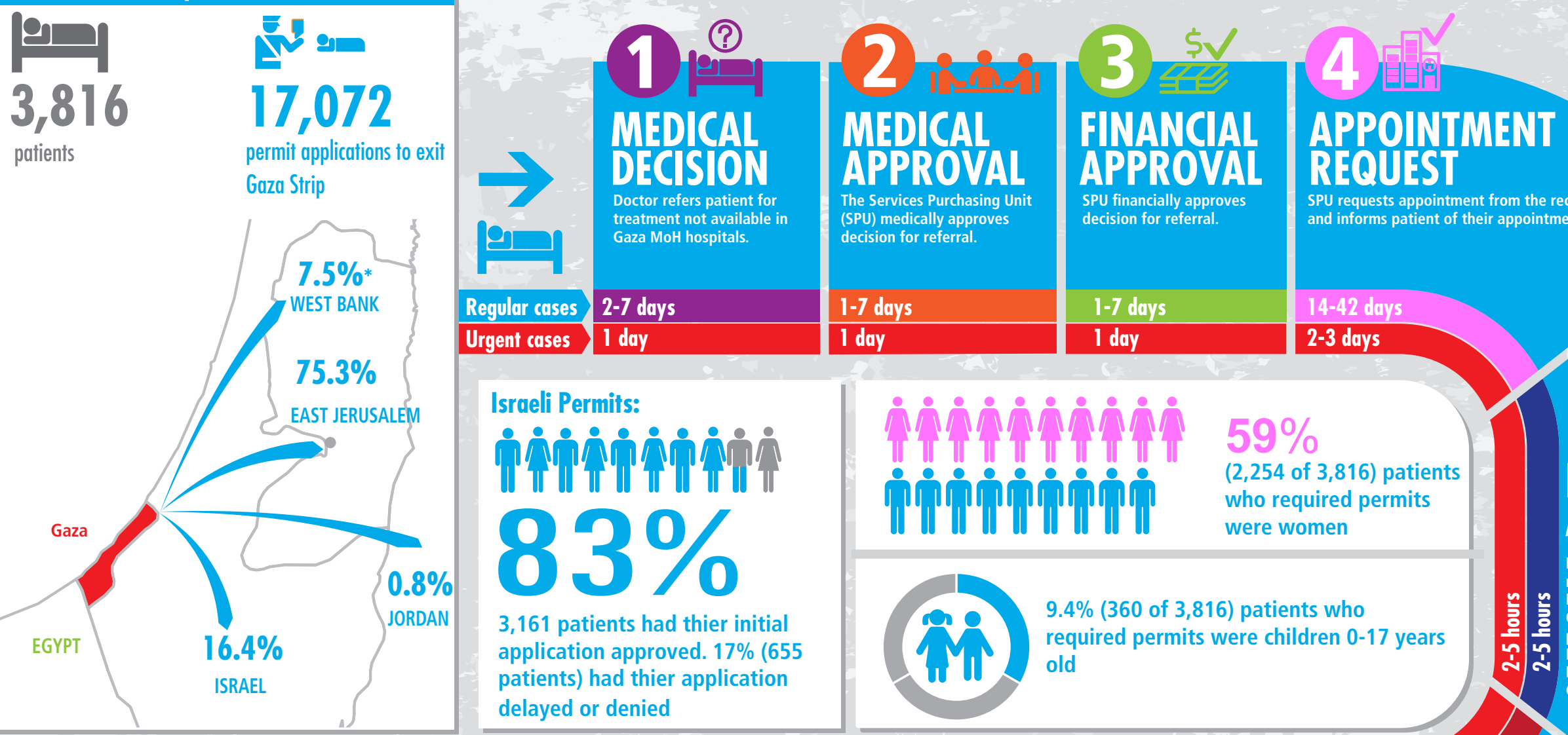

\title{
5-7 hours
}

\section{5-7 hours}

TRAVEL BACK TO GAZA

Patients visiting West Bank hospitals must cross checkpoints into Jerusalem, as well as having to pass through Erez

checkpoint into Gaza. Each checkpoint means further delays

and the possibility of interrogation or arrest.

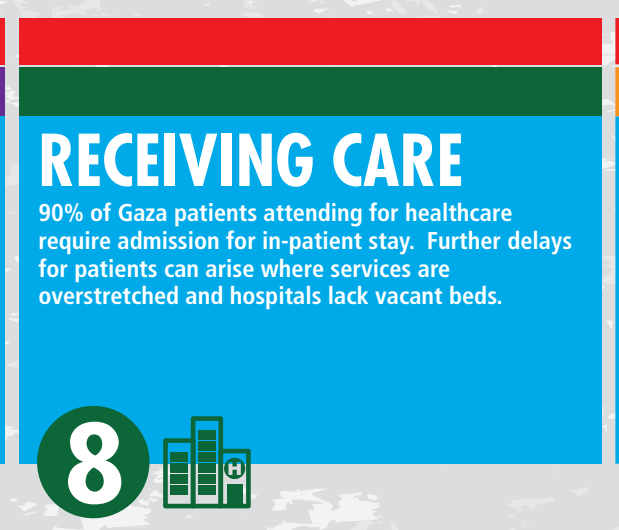

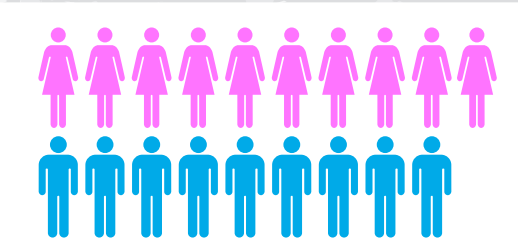

$59 \%$

$(2,254$ of 3,816$)$ patients

who required permits were women

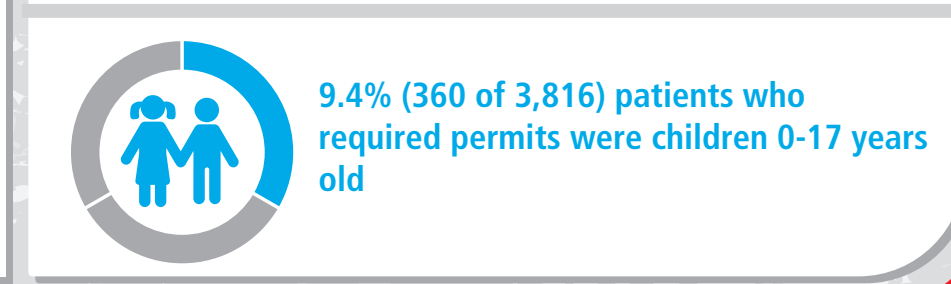

\begin{tabular}{l} 
5-7 hours \\
\hline 5-7 hours
\end{tabular}

CROSSING EREZ CHECKPOINT Patient passes through the de facto authority checkpoint, Palestinian Authority registration post and Israeli (Erez) checkpoint to exit Gaza,
including a $1 \mathrm{~km}$ corridor from the Palestinian to the Israeli terminals. including a $1 \mathrm{~km}$ corridor from the Palestinian to the Israeli terminals.
At the Erez terminal, patients undergo a body search, luggage search At the Erez terminal, patients undergo a body search, luggage search
and permit checks. Patients and companions may be interrogated, and permit checks. Patie
arrested or detained.

7

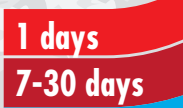

\section{PERMIT PROCESS}

CLA processes permit applications. Patient waits for a response by text through the HLO, which usually comes
their appointment date. 